\title{
Depletion of Progranulin Reduces GluN2B-Containing NMDA Receptor Density, Tau Phosphorylation, and Dendritic Arborization in Mouse Primary Cortical Neurons $\underline{\underline{[}}$
}

\author{
Francesca Longhena, Michela Zaltieri, Jessica Grigoletto, Gaia Faustini, Luca La Via, \\ Roberta Ghidoni, Luisa Benussi, Cristina Missale, PierFranco Spano, and Arianna Bellucci
}

Department of Molecular and Translational Medicine, University of Brescia, Brescia, Italy (F.L, M.Z., J.G., G.F., L.L.V., C.M., P.S., A.B.) and Molecular Markers Laboratory, IRCCS Instituto Centro San Giovanni di Dio Fatebenefratelli, Brescia, Italy (R.G., L.B.)

\begin{abstract}
Loss-of-function mutations in the progranulin (PGRN) gene are a common cause of familial frontotemporal lobar degeneration (FTLD). This age-related neurodegenerative disorder, characterized by brain atrophy in the frontal and temporal lobes and such typical symptoms as cognitive and memory impairment, profound behavioral abnormalities, and personality changes is thought to be related to connectome dysfunctions. Recently, PGRN reduction has been found to induce a behavioral phenotype reminiscent of FTLD symptoms in mice by affecting neuron spine density and morphology, suggesting that the protein can influence neuronal structural plasticity. Here, we evaluated whether a partial haploinsufficiency-like PGRN depletion, achieved by using RNA interference in primary mouse cortical neurons, could modulate GluN2B-containing $N$-methyl-
\end{abstract}

D-aspartate (NMDA) receptors and tau phosphorylation, which are crucially involved in the regulation of the structural plasticity of these cells. In addition, we studied the effect of PGRN decrease on neuronal cell arborization both in the presence and absence of GluN2B-containing NMDA receptor stimulation. We found that PGRN decline diminished GluN2B-containing NMDA receptor levels and density as well as NMDA-dependent tau phosphorylation. These alterations were accompanied by a marked drop in neuronal arborization that was prevented by an acute GluN2Bcontaining NMDA receptor stimulation. Our findings support that PGRN decrease, resulting from pathogenic mutations, might compromise the trophism of cortical neurons by affecting GluN2Bcontaning NMDA receptors. These mechanisms might be implicated in the pathogenesis of FTLD.

\section{Introduction}

Progranulin (PGRN), also known as granulin (GRN)-epithelin precursor, is a secreted pleiotropic growth factor controlling the maintenance and regulation of the homeostatic dynamics of normal tissue development, proliferation, regeneration, immunity, and inflammation (Jian et al., 2013; Petkau and Leavitt, 2014). Its role has been widely studied in the field of infectious diseases, wound healing, tumorigenesis, and most recently, neurodegenerative diseases. Indeed, GRN nonsense mutations, producing aberrant mRNA transcripts undergoing non-sense-mediated decay, have been found to be responsible for the onset of familial forms of frontotemporal lobar degeneration (FTLD) (Baker et al., 2006; Cruts et al., 2006; Gijselinck et al., 2008; Skoglund et al., 2011). All the pathogenic GRN mutations identified thus far cause the disease through a uniform mechanism, i.e., loss of functional progranulin or haploinsufficiency with FTLD resulting from progranulin depletion rather than from the accumulation of the mutant protein (Ghidoni et al., 2008, 2012) (Finch et al.,

This work was supported by the Fondazione Cariplo Project 2009-2633, and by the Italian Ministry of Education, Universities, and Research (Ex 60\%). doi.org/10.1124/jpet.117.242164.

S This article has supplemental material available at jpet.aspetjournals.org.
2009; Sleegers et al., 2009). FTLD is a neurodegenerative disorder characterized by prominent atrophy of the frontal and temporal lobes of the brain and occurring in mid-life and later. The typical symptoms encompass profound behavioral abnormalities, personality changes, progressive aphasia, as well as other types of cognitive and memory impairment (McKhann et al., 2001).

In FTLD patients carrying a GRN mutation, the main pathologic signature on magnetic resonance imaging is the involvement of the fronto-temporo-parietal circuits, with prominent parietal and asymmetric atrophy (Whitwell et al., 2007; Rohrer et al., 2010; Bozzali et al., 2013), impaired connectivity in long-distance intrahemispheric tracts (Rohrer et al., 2013), salience network disruption (Borroni et al., 2012), and impaired brain oscillatory activity (Moretti et al., 2016).

Cortical atrophy and white matter tract abnormalities in frontalparietal circuits can be detected at least a decade before the estimated onset of symptoms in asymptomatic mutation carriers (Pievani et al., 2014; Rohrer et al., 2015), suggesting that connectome dysfunctions could be crucial for disease manifestation.

In the brain, PGRN is expressed in both microglial cells and neurons but not in astrocytes. Although GRN expression in neurons increases with cell maturation, its expression in microglia varies in relation to the activation state of the cells and can be enhanced in response to excitotoxic injury (Petkau et al.,

ABBREVIATIONS: ANOVA, analysis of variance; BSA, bovine serum albumin; DIV, day(s) in vitro; FTLD, frontotemporal lobar degeneration; GRN, granulin; ICC, immunocytochemistry; IHC, immunohistochemistry; KRS, Krebs-Ringer solution; LDH, lactate dehydrogenase; NMDA, N-methyl-Daspartate; P0, newborn; PBS, phosphate-buffered saline; PRGN, progranulin; RNAi, RNA interference; SCR, scramble. 
2010). Complete deficiency of PGRN has been found to dysregulate microglial activation, contribute to increased neuron loss with injury, and promote circuit-specific synaptic pruning via complement activation (Lui et al., 2016; Martens et al., 2012). However, more recent studies reported differences in the effect of protein deficiency in multiple inbred mouse strains in relation to neuron spine density and morphology (Petkau et al., 2016), thus suggesting a complex role for PGRN in the regulation of neuronal resilience. Consistently, a biased lack of PGRN in mice can induce behavioral abnormalities that are reminiscent of FTLD symptoms such as age-dependent social and emotional deficits. These alterations occur in the absence of gliosis or increased expression of tumor necrosis factor- $\alpha$, thus suggesting that FTLD-related deficits can develop in the absence of detectable neuroinflammatory changes, and supporting an important effect of PGRN deficiency on neurons (Filiano et al., 2013). On the other hand, both full length PGRN and GRN-epithelin peptide promote neuronal survival and neurite outgrowth in primary rat cortical and motor neurons (Van Damme et al., 2008; Ryan et al., 2009). PGRN has also been implicated in the regulation of motor neuron development as well as neurite outgrowth and branching (Chitramuthu et al., 2010; Laird et al., 2010), and gene silencing of PGRN in primary hippocampal neurons affects neuronal connectivity (Tapia et al., 2011). In line with this evidence, we demonstrated (Benussi et al., 2016) that the presence of GRN null mutations strongly reduces the number of released exosomes, microvesicles serving as intercellular communication tools that can be released by neurons following synaptic activation (Laulagnier et al., 2017).

Collectively, these studies support the conclusion that PGRN deficiency can affect neuronal structural plasticity.

Of note, this latter process can be finely regulated by the activity of glutamate $N$-methyl-D-aspartate (NMDA) receptors (Carpenter-Hyland and Chandler, 2007; Mony et al., 2009; Wyllie et al., 2013; Stein et al., 2015), those containing the GluN2B subunit in particular (Williams et al., 2003; El Gaamouch et al., 2012). GluN2B-containing NMDA receptors have been found to be implicated in the control of tau phosphorylation in cortical and hippocampal neurons (Laurier-Laurin et al., 2014; Arendt et al., 2015) and NMDA receptors can mediate taudependent neuronal degeneration (Tackenberg et al., 2013). Therefore, the resilience of cortical and hippocampal neurons, which are vulnerable in FTLD, may be particularly sensitive to subtle homeostatic changes in NMDA receptor function and tau post-translational modifications.

On this basis, we aimed at studying whether and how PGRN reduction could modulate the structural plasticity of primary cortical neurons by affecting the expression of NMDA receptors and tau phosphorylation. We found that PGRN gene silencing decreased GluN2B-containing NMDA receptor density and activity as well as NMDA-dependent tau phosphorylation without affecting cell viability. These events were accompanied by the onset of a marked reduction in dendritic arborization of cortical neurons that could be prevented by an acute stimulation of GluN2Bcontaining NMDA receptors.

\section{Materials and Methods}

Animals. C57BL/6J mice were used to prepare primary neuronal cell cultures and to characterize PGRN expression in the adult brain. Animals were bred and housed in the Animal House facility of the
Department of Molecular and Translational Medicine of the University of Brescia with food and water and maintained on a 12-hour light/dark cycle at a room temperature $23^{\circ} \mathrm{C}$. All experiments and surgical procedures conformed to the National Research Guide for the Care and Use of Laboratory Animals and were approved by the Animal Research Committees of the University of Brescia (protocol permit nos. 03/12 and 04/12). All efforts were made to minimize animal suffering and to reduce the number of animals used.

Primary Cortical and Hippocampal Neuronal Cultures. Primary neuronal cultures from cortical and hippocampal tissues were dissected from C57BL/6J newborn pups at day 0. Briefly, after mechanical dissociation the single cells were resuspended in Neurobasal-A medium (Gibco/Thermo Fisher Scientific, Milan, Italy), containing $100 \mu \mathrm{g} / \mathrm{ml}$ penicillin, $100 \mu \mathrm{g} / \mathrm{ml}$ streptomycin (Sigma-Aldrich, Milan, Italy), $0.5 \mathrm{mM}$ glutamine (EuroClone, Milan, Italy), and 1\% B27 supplement (Gibco). Cells were then centrifuged, and cell count and viability assays were performed using the Trypan blue exclusion test. Cells were seeded onto poly-D-lysine-coated glass coverslides in 24-well plates ( $14 \mu \mathrm{g} / \mathrm{ml}$ ) for immunocytochemistry (70,000 cells/well), or onto poly-D-lysine-coated Petri dishes $(10 \mu \mathrm{g} / \mathrm{ml})$ for biochemical analyses $\left(800,000\right.$ cells/dish). Cells were maintained at $37^{\circ} \mathrm{C}$ under a humidified atmosphere of $5 \% \mathrm{CO}_{2}$ and $95 \% \mathrm{O}_{2}$ for at least 10 days in vitro (DIV) to allow their maturation prior to their use. Characterization experiments on cell cultures showed that they contained 95\% neuronal cells and 5\% astrocytes (results not shown).

RNA Interference. Cortical neurons were subjected to RNA interference (RNAi) at DIV 10 with four different siRNA sequences for PGRN gene silencing (Dharmacon, Chicago, IL). A nonsilencing RNA sequence, scramble (SCR), was used as negative control. The optimal targeting and SCR RNA concentrations for gene silencing were estimated to be $25 \mathrm{nM}$.

All the sequences were diluted in Opti-MEM (Gibco) and then transfected into cells using INTERFERin (Polyplus-Transfection, Illkirch, France) according to the manufacturer's instructions.

Lactate Dehydrogenase Activity-Based Cytotoxicity Assay. Cell culture media from either control primary neuronal cultures or cultures treated with siRNA or SCR were centrifuged at $250 \mathrm{~g}$ for 4 minutes to remove the cells debris. Lactate dehydrogenase ( $\mathrm{LDH})$ activity measurements were performed using a commercially available assay (Sigma-Aldrich) according to the manufacturer's instructions. The LDH activity was measured at 490 and $600 \mathrm{~nm}$ with a spectrophotometer.

Measurement of Intracellular Calcium Concentrations. Regulation of cytosolic free $\mathrm{Ca}^{2+}$ concentration by NMDA in primary cortical neuronal cells was investigated by microfluorimetry in single cells according to Navarria et al. (2015). The cells were plated onto $50-\mathrm{ng} / \mathrm{ml}$ poly-L-lysine-coated glass coverslips at a density of $0.5 \times 10^{3} \mathrm{cells} / \mathrm{cm}^{2}$ and cultured as described above. At DIV 10, cells were loaded with the $\mathrm{Ca}^{2+}$-sensitive fluorescent dye Fura-2 AM (Sigma-Aldrich). Incubation was carried out for 60 minutes at $37^{\circ} \mathrm{C}$ in Krebs-Ringer solution (KRS) (125 mM NaCl, $5 \mathrm{mM} \mathrm{KCl}, 1.2 \mathrm{mM}$ $\mathrm{KH}_{2} \mathrm{PO}_{4}, 2 \mathrm{mM} \mathrm{CaCl}$, 25 mM HEPES-NaOH, 6 mM glucose, $\mathrm{pH}$ 7.4) containing $1.3 \mathrm{mg} / \mathrm{ml}$ bovine serum albumin (BSA) and $4 \mathrm{mM}$ Fura-2 AM. They were then mounted in a $22-\mathrm{mm}$ holder creating a chamber with the coverslips on the bottom. Fura-2 emission was monitored by using an inverted fluorescence microscope (Nikon Diaphot) associated with an intensified charge-coupled device camera (MIRA-100 TE; Applied Imaging, Gateshead, UK), which recorded the 510-nm fluorescence emission in neurons excited through narrow band-pass filters (340 and $380 \mathrm{~nm}$ ). The background was subtracted and the amount of free $\mathrm{Ca}^{2+}$ within the cell bodies was calculated from the ratio of $340 / 380 \mathrm{~nm}$ obtained every $3-4$ seconds. Calibration was made according to external standards of $\mathrm{Ca}^{2+}$ and Fura-2. Fluorescent image acquisition and analysis were performed using the MIRAcal (Multiple Image Ratioing and Analysis with Calibration System; Applied Imaging, Gateshead, UK). Cells were exposed to $500 \mu \mathrm{M}$ NMDA and $100 \mu \mathrm{M}$ glycine for 200 seconds in the chamber containing $\mathrm{Mg}^{2+}$-free KRS. To check whether $\mathrm{Ca}^{2+}$ release was dependent 
on GluN2B-containing NMDA receptors, cells were exposed to $1 \mu \mathrm{M}$ ifenprodil, which was added 30 seconds before glutamate and glycine stimulation and maintained for the entire experiment. Cells were then washed with $\mathrm{Ca}^{2+}$-free solution and returned to the KRS. To check whether analyzed cells were sensitive to depolarizing stimuli, at the end of each experiment, $100 \mathrm{mM} \mathrm{KCl}$ stimulation was performed. Plateau values of $\left[\mathrm{Ca}^{2+}\right]$ increase were calculated from the mean of four determinations taken at 20,40,60, 80, and 120 seconds after application of stimulating agents.

Cell Culture Treatments. To evaluate the effect of NMDA receptor stimulation on neuronal arborization and tau phosphorylation in siRNA-exposed neurons, at 24 hours from gene silencing the cells were exposed to $500 \mu \mathrm{M}$ NMDA and $100 \mu \mathrm{M}$ glycine in $\mathrm{Mg}^{2+}$-free KRS for 10 minutes. Pretreatment with the GluN2B antagonist ifenprodil was performed in the same conditions with the addition of $10 \mu \mathrm{M}$ ifenprodil to $\mathrm{Mg}^{2+}$-free KRS 20 minutes prior to NMDA + glycine. Cells were then incubated again with their original cell culture media. A fraction of siRNA-exposed cells were subjected to media changes without the addition of NMDA and glycine as a control.

Immunocytochemistry. For immunocytochemistry (ICC) cells were fixed by incubation for 15 minutes in 3\% paraformaldehyde/3\% sucrose made up in phosphate-buffered saline (PBS) $1 \mathrm{M}, \mathrm{pH} 7.4$, and then stored in PBS containing $0.05 \%$ sodium azide. Slides were incubated for 10 minutes at $25^{\circ} \mathrm{C}$ in a permeabilization solution composed by $20 \%$ methanol in PBS containing $0.1 \%$ Triton X-100, then 30 minutes in blocking solution composed by $2 \%(\mathrm{v} / \mathrm{v})$ normal goat serum (Sigma-Aldrich) plus 3\% (w/v) BSA (Sigma-Aldrich) in PBS containing $0.1 \%$ Triton $\mathrm{X}-100$, and then overnight at $4^{\circ} \mathrm{C}$ with primary antibody at the optimal working dilution made up in blocking solution. On the following day, cells were incubated for 1 hour at $25^{\circ} \mathrm{C}$ with the fluorescent secondary antibody diluted in PBS containing $0.1 \%$ Triton X-100 with $0.1 \%$ BSA. For double-labeling, at the end of this incubation cells underwent another cycle of staining. Cell nuclei were counterstained with Hoechst 2495 (Sigma-Aldrich). Coverslips were then mounted on glass slides with Vectashield mounting medium (Vector Laboratories, Burlingame, CA).

Immunohistochemistry. For immunohistochemistry (IHC), mice were anesthetized with chloral hydrate $(400 \mathrm{mg} / \mathrm{kg}$, i.p.) and were perfused transcardially with $4 \%$ ice-cold paraformaldehyde in $0.1 \mathrm{M}$ phosphate buffer, pH 7.2. For newborn (P0) pups, mice were decapitated and the whole head was fixed in $4 \%$ ice-cold paraformaldehyde overnight. At 4 hours postfixation, brains were put in $18 \%$ sucrose, and the day after, $30-\mu \mathrm{m}$ coronal sections were cut with a cryostat (Leica Biosystems, Nußloch, Germany).

Free-floating sections were washed with PBS containing $0.3 \%$ Triton $\mathrm{X}-100$ and incubated for 30 minutes at $25^{\circ} \mathrm{C}$ in a permeabilization solution composed by $20 \%$ methanol in PBS containing $0.3 \%$ Triton $\mathrm{X}-100$, then 1 hour in blocking solution composed by $2 \%$ (v/v) normal goat serum (Sigma-Aldrich) plus 3\% (w/v) bovine serum albumin (BSA; Sigma-Aldrich) in PBS containing 0.3\% Triton X-100, and then overnight at $4^{\circ} \mathrm{C}$ with primary antibody at the optimal working dilution made up in blocking solution. On the following day, cells were incubated for 1 hour at $25^{\circ} \mathrm{C}$ with the fluorescent secondary antibody diluted in PBS containing $0.3 \%$ Triton X-100 with $0.1 \%$ BSA. For double-labeling, at the end of this incubation, cells underwent another cycle of staining. Cell nuclei were counterstained with Hoechst 2495 (Sigma-Aldrich). Coverslips were then mounted on glass slides with the Vectashield mounting medium (Vector Laboratories).

Antibodies. A list of the primary antibodies used for this study is summarized in Table 1. Secondary antibodies used for IHC and ICC were anti-mouse $\mathrm{Cy} 3$-conjugated, anti-rabbit $\mathrm{Cy} 3$ - or FITC-conjugated (Jackson ImmunoResearch, Baltimore, MD), and anti-sheep ALEXA488-conjugated (Molecular Probes, Eugene, OR).

Secondary antibodies used for Western blot were anti-mouse, antirabbit (Santa Cruz Biotechnology, Santa Cruz, CA) and anti-sheep (Southern Biotech, Birmingham, AL) horseradish peroxidase-conjugated.

Confocal and Fluorescence Microscopy. Fixed cells and mouse brain sections were observed by means of an inverted light/epifluorescence microscope (Olympus IX50; Olympus, Milan, Italy) or by means of a Zeiss confocal laser microscope (Carl Zeiss S.p.A., Milan, Italy), with the laser set on $1=405-488-543 \mathrm{~nm}$ and the height of the sections scanning $=1 \mu \mathrm{m}$. Images $(512 \times 512$ pixels $)$ were then reconstructed using LSM Image Examiner (Carl Zeiss S.p.A) and Adobe Photoshop 7.0 (Adobe Systems, Mountain View, CA) software.

Sholl Analysis. A Sholl analysis of single neurons in the primary cortical neuronal cell cultures was performed manually on the basis of ImageJ software (NIH, Bethesda, MD). After MAP-2 ICC, randomly chosen neurons were analyzed. The number of intersections of the neurite tree with increasing circular perimeters from the center of the soma was counted every $30 \mu \mathrm{m}$ by using a calibrated concentric circle mask. The collected data were plotted by using GraphPad Prism 4 and analyzed as described below.

Western Blot. For total protein extraction, either cell pellets or mouse brain tissue was lysed in a buffer containing $50 \mathrm{mM}$ Tris-HCl, $\mathrm{pH} 7.4,150 \mathrm{mM} \mathrm{NaCl}, 0.5 \% \mathrm{Na}$ deoxycholate, $0.1 \% \mathrm{Na}$ dodecyl sulfate, $2 \mathrm{mM}$ EDTA, $0.1 \mathrm{mM}$ phenylmethylsulfonyl fluoride, $1 \mathrm{mM}$ $N$-ethylmaleimide, $1 \mathrm{mM}$ Na orthovanadate, $1 \%$ Nonidet P- $40, \mathrm{mM}$ $\mathrm{NaF} 1$, and protease inhibitor cocktail (Roche Diagnostics, Mannheim, Germany). For membrane protein extraction, cell pellets were homogenized in Nonidet P-40 buffer $(\mathrm{NaCl} 150 \mathrm{mM}, 50 \mathrm{mM}$ HEPES, $\mathrm{pH} \mathrm{7.4,} \mathrm{1 \%} \mathrm{Nonidet} \mathrm{P-40)} \mathrm{and} \mathrm{nuclei} \mathrm{and} \mathrm{cell} \mathrm{debris} \mathrm{were}$ eliminated by centrifugation of the homogenate at $500 \mathrm{~g}$ for $10 \mathrm{~min}$ utes at $4^{\circ} \mathrm{C}$. Pellets were discarded and supernatants were then centrifuged at $100,000 \mathrm{~g}$ for 1 hour at $4^{\circ} \mathrm{C}$. The resulting pellet was then dissolved in lysis buffer and centrifuged at $100,000 \mathrm{~g}$ at $4^{\circ} \mathrm{C}$ for 1 hour. This final pellet containing membrane fractions was used for Western blot analysis. Protein concentrations in the samples were measured by using the Bradford assay (Pierce, Rockford, IL). Equal amounts of proteins $(30 \mu \mathrm{g})$ were run on $4-12 \%$ Invitrogen Novex NuPAGE 4-12\% Bis-Tris Protein Gels (Fisher Scientific, Waltham, MA) and blotted on a polyvinylidene difluoride Immobilon-P membrane (Millipore, Milan, Italy). Densitometric analysis of bands was performed by means of Gel Pro Analyzer version 6.0. (Media Cybernetics, Bethesda, MD). Band densities were normalized to either glyceraldehyde-3-phosphate dehydrogenase or $\alpha$-tubulin levels as a control of equal loading of samples. For membrane protein extracts GluN1 and GluN2B, bands were normalized to the membrane protein amyloid precursor protein levels as a control for equal loading.

Analysis of GluN2B, GluN1 and PSD-95 Density. Images were obtained by using a Zeiss LSM510 Laser scanning confocal Microscope (Ziess, Oberkochen, Germany) with a $63 \times$ oil-immersion objective. All images within a single experiment were acquired using equivalent settings by an individual who was blind to treatment conditions. Neurons were selected at random from each quadrant of the coverslip by PGRN staining. For each neuron, three dendrites were chosen and their length was measured from phase contrast images. To quantify the ICC data from the three dendrites of each neuron, the neurons were chosen randomly for image acquisition and processed using Image $\mathrm{J}$ software ( 10 cells from each condition from three independent experiments were acquired). For each experiment, the efficiency of PGRN gene silencing was confirmed by the analysis of the ICC signal, and images in each channel were captured using the same exposure time across all fixed cells. Images were acquired as grayscale from individual channels and pseudocolor overlays were prepared using Adobe Photoshop. To quantify GluN1, GluN2B, and PSD-95 density per dendrite length in ICC photomicrographs, we selected regions using Image $J$ software, subjected the digital images to a user-defined intensity threshold to select clusters (the same threshold sets were used for each independent experiment), and measured for cluster intensity, number, and area. All imaging and analysis were blind to gene-silencing and treatment condition. All the measurements were normalized to control-cell values.

Statistical Analysis. Each experiment was replicated at least three times, with each experimental condition produced either in duplicate or triplicate. Differences between 88- and 62-kDa PGRN 
TABLE 1

List of the primary antibodies used for Western blot, ICC, and IHC

\begin{tabular}{|c|c|c|c|c|c|c|}
\hline \multirow{2}{*}{ Antibody } & \multirow{2}{*}{ Specificity } & \multirow{2}{*}{ Source } & \multicolumn{3}{|c|}{ Dilution } & \multirow{2}{*}{ Host } \\
\hline & & & Western blot & ICC & $\mathrm{IHC}$ & \\
\hline PGRN & AA $18-589$ & R\&D System & $1: 500$ & $1: 400$ & $1: 500$ & Sheep \\
\hline APP & $\mathrm{N}$-terminal & Millipore & $1: 500$ & - & - & Mouse \\
\hline CD11b & - & AbD Serotec & - & - & $1: 1000$ & Rat \\
\hline GAD-67 & - & Millipore & - & $1: 1000$ & - & Mouse \\
\hline GAPDH & & Millipore & $1: 5000$ & - & & Mouse \\
\hline GFAP & - & DAKO & - & - & $1: 500$ & Rabbit \\
\hline MAP-2 & & Millipore & - & $1: 300$ & - & Rabbit \\
\hline GluN1 & C-terminal & Santa Cruz Biotechnology & $1: 1500$ & - & - & Rabbit \\
\hline GluN2B & C-terminal & Santa Cruz Biotechnology & $1: 1500$ & - & - & Rabbit \\
\hline PHF1 & $\mathrm{Tau}^{\mathrm{pS} 396 / \mathrm{pS} 404}$ & P. Davies & $1: 1000$ & - & - & \\
\hline PSD-95 & & Cell Signaling Technology & - & 1:1000 & - & Mouse \\
\hline p-TAU(Ser262) & $\mathrm{Tau}^{\mathrm{pS} 262}$ & Santa Cruz Biotechnology & $1: 1000$ & - & - & Rabbit \\
\hline Tau 46 & C-terminal & Cell Signaling Technology & $1: 1000$ & - & - & Mouse \\
\hline$\alpha$-Tubulin & & Sigma-Aldrich & $1: 5000$ & - & - & Mouse \\
\hline
\end{tabular}

APP, amyloid precursor protein; GADPH, glyceraldehyde 3-phosphate dehydrogenase; GFAP, glial fibrillary acidic protein.

levels assayed by Western blot in cortical and hippocampal samples from control mice were analyzed by two-way analysis of variance (ANOVA) + Bonferroni's multiple comparison test. Differences in 62-kDa PGRN, GluN1, and GluN2B levels between cortical and hippocampal neurons were analyzed by Student's $t$ test. The effect of PGRN gene silencing on PGRN levels and $\mathrm{LDH}$ release was analyzed by one-way ANOVA followed by Newman-Keuls postcomparison test. The same analysis was used to evaluate differences in GluN1 and GluN2B levels, intracellular $\mathrm{Ca}^{2+}$ load, as well as GluN1, GluN2B, and PSD-95 distribution in control, SCR-treated, and siRNA-exposed cells. Two-way ANOVA + Bonferroni's postcomparison test was used to analyze the data from Sholl analysis.

\section{Results}

\section{Age-Related Differences in the Expression of the Mature 62-kDa and Glycosylated 88-kDa Form of PGRN in Cortical and Hippocampal Extracts of C57BL/6J Mice}

Since the aim of this work was to estimate the effect of PGRN reduction in primary neurons, we first probed the expression of PGRN in the cortex and hippocampus of C57BL/6J mice during aging (Fig. 1, A-C). By Western blot analysis we found that newborn mice only express the mature nonglycosylated form of the $62-\mathrm{kDa}$ protein. The expression of this form of the protein was significantly higher in cortical extract compared with hippocampal extracts (Fig. 1, A and C). However, the expression of nonglycosylated PGRN was significantly reduced both in the hippocampus and cortex of 1-, 8-, and 12-month-old mice compared with newborn mice (Fig. 1, A and C). In parallel, the levels of the glycosylated $88-\mathrm{kDa}$ PGRN form, that was low at P0, strongly increased in the cortical and hippocampal extracts from C57BL6J mice along with aging (Fig. 1, A and B). Of note, the levels of 88-kDa glycosylated PGRN in the hippocampal extracts from 12-month-old mice were found to be significantly higher than those observed in 1- and 8-month-old mice (Fig. 1, A and B). Conversely, the levels of 88-kDa PGRN in the cortical extracts of 1-, 8-, and 12-month-old mice were comparable (Fig. 1, A and B).

\section{Characterization of Primary Cortical and Hippocampal Neuronal Cell Cultures}

To definitively choose whether to work on cortical or hippocampal neurons we probed PGRN levels in the cell cultures prepared from newborn P0 mice by Western blot. In line with the above observations we found that at 10 DIV these cells only expressed the 62-kDa PGRN form and its levels were significantly higher in cortical neurons compared with hippocampal neurons (Fig. 2A). These findings indicated that cortical neurons may constitute a more representative model to study the effects of PGRN gene silencing in vitro.

Since one of our aims was to probe the effect of PGRN gene silencing on the GluN2B-containing NMDA receptor, we also studied the levels of GluN1 and GluN2B in primary cortical and hippocampal neuronal protein extracts at DIV 10. By Western blot, we found that the expression of GluN1 and GluN2B was significantly higher in cortical neurons compared with hippocampal neurons (Fig. 2B). These changes were not the result of differences in cell maturation, as confirmed by the analysis of neuronal morphology in phase contrast images (Fig. 2C) and by the fact that both cortical and hippocampal neurons showed a good degree of expression of mature neuronal markers such as NeuN (Fig. 2D), MAP-2 (Fig. 2E), and GAD-67 (Fig. 2F).

\section{Experimental Design and Evaluation of PGRN Gene Silencing and Cell Viability}

In this study we aimed at evaluating whether PGRN reduction could modulate neuronal structural plasticity through the modulation of GluN2B-containing NMDA receptor and tau phosphorylation. For this reason we used primary cortical neurons cultured for 10 DIV prepared from newborn P0 mice (Fig. 3A). Cells were subjected to silencing RNA (siRNA)-based RNA interference at DIV 10. Four different siRNA sequences (Fig. 3B) were tested. Efficacy of PGRN gene silencing and NMDA and tau phosphorylation were evaluated at 72 hours from RNAi, cell viability was probed at 96 hours from RNAi, whereas neuronal morphology 
A

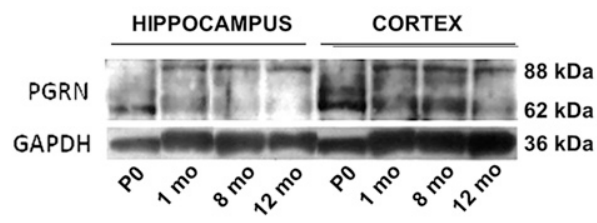

$88 \mathrm{kDa}$

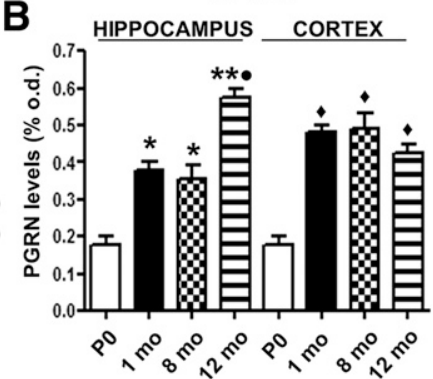

$62 \mathrm{kDa}$

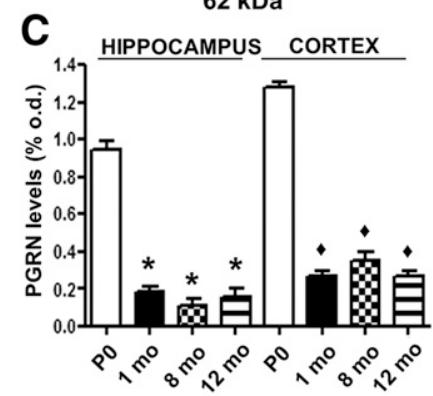

Fig. 1. Levels and distribution of PGRN in the cortex and hippocampus of C57BL/6J mice during aging. (A) Representative Western blot images showing the levels of 62- and 88-kDa PGRN in the hippocampus and cortex of newborn (P0), 1-month-, 8-month-, and 12-month-old mice. Glyceraldehyde-3-phosphate dehydrogenase (GAPDH) bands are shown as a control of sample loading. (B) The histogram shows the mean + S.E.M. optical density (o.d.) of the 88-kDa PGRN-immunopositive bands when normalized to GAPDH bands' o.d. Please note the statistically significant increase of 88 -kDa hippocampal and cortical PGRN during mouse aging. $* P<0.05$ vs. $\mathrm{P} 0$, $* * P<0.01$ vs. $\mathrm{P} 0, \bullet P<0.05$ vs. 1 - and 8 -month-old, $\bullet P<0.001$ vs. P0, two-way ANOVA plus Bonferroni's postcomparison test $(N=4$ triplicates for each of the experimental conditions analyzed). (C) Histogram showing the relative o.d. (mean + S.E.M.) of $62-\mathrm{kDa}$ PGRN-immunopositive bands when normalized to o.d of GAPDH bands. A statistically significant decrease in the protein in cortical and hippocampal neurons during mouse aging was evident. $* P<0.001$ vs. P0; $\bullet<0.001$ vs. P0, two-way ANOVA plus Bonferroni's postcomparison tests $(N=4$ triplicates for each of the experimental conditions analyzed).

and GluN2B and PGRN expression were analyzed at 120 hours from gene silencing. A schematic representation of our experimental design is showed in Fig. 3A.
By Western blot we found that siRNA sequence 4 was able to induce an efficient $60 \%$ reduction in PGRN levels that was evident at 72 hours from RNAi (Fig. 3C), without affecting cell

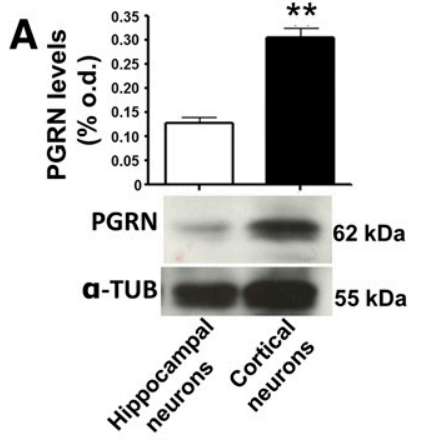

C

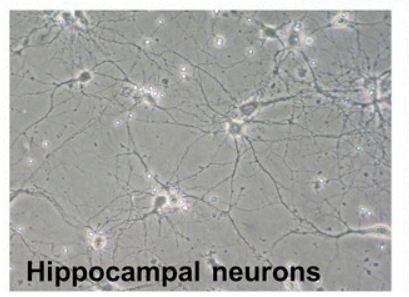

Phase contrast

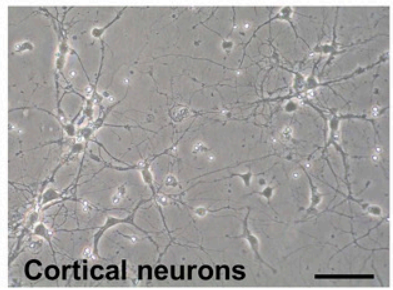

$\mathbf{E}$
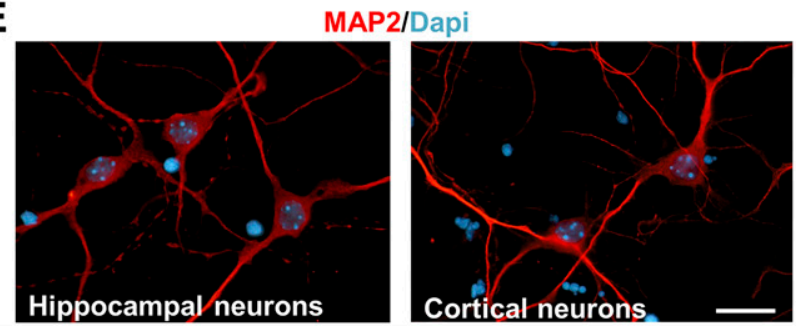

B

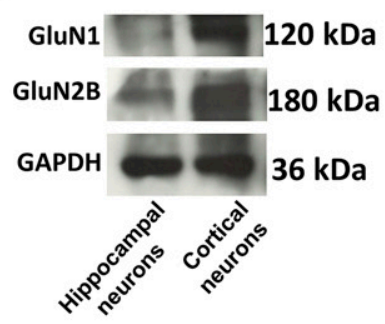

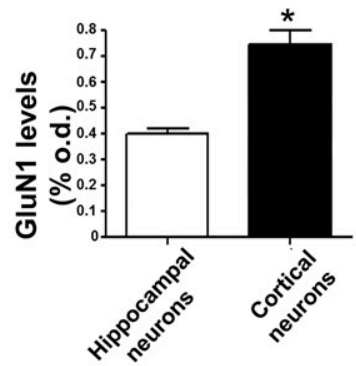

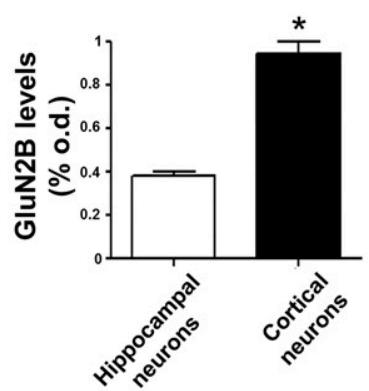

D

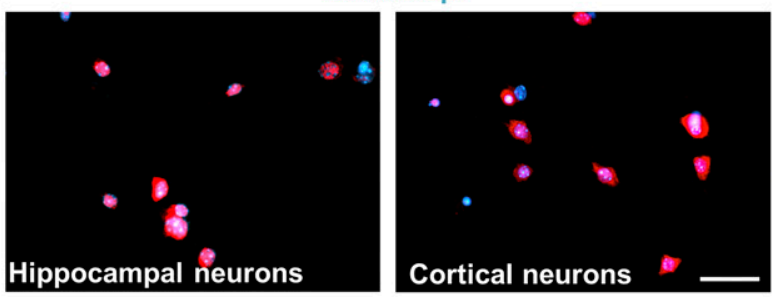

$\mathbf{F}$

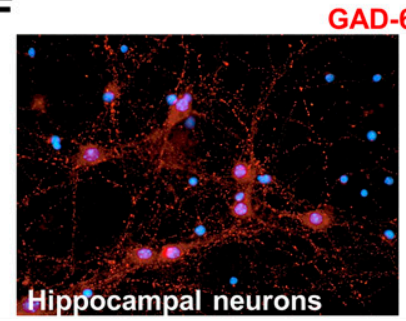

Fig. 2. PGRN- and GluN2B-containing NMDA receptor levels and maturation of primary cortical and hippocampal neuronal cells at 10 DIV. (A) Histogram showing the levels of 62-kDa PGRN (mean +S.E.M.) in primary mouse cortical and hippocampal neurons. Representative immunoblotting bands are shown below the bars. Please note that cortical neurons express higher levels of the protein; ** $P<0.01$ Student's $t$ test $(N=5$ triplicates for each group). (B) GluN1 and GluN2B levels in primary mouse cortical and hippocampal neuronal cell cultures. Representative immunoblottings are shown on the left. The histograms show that GluN1 and GluN2B levels (mean + S.E.M.) were significantly higher in cortical neurons than in hippocampal neurons; $* P<0.001$ Student's $t$ test $(N=4$ triplicates for each experimental condition analyzed). (C) Phase contrast images showing the morphology of cortical and hippocampal neuronal cells at 10 DIV. Scale bar, $280 \mu \mathrm{m}$. (D) NeuN ICC shows the presence of mature NeuN-positive neurons in both primary cortical and hippocampal neuronal cell cultures. Scale bar, $120 \mu \mathrm{m}$. (E) MAP-2 immunopositivity in cortical and hippocampal neurons. Scale bar, $50 \mu \mathrm{m}$. (F) GAD-67 ICC shows the presence of mature GABAergic neurons. Scale bar, $100 \mu \mathrm{m}$. 
A

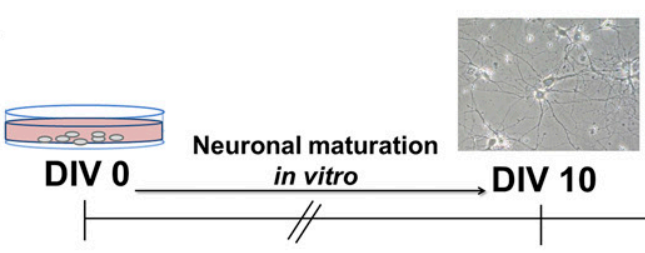

Preparation of primary neuronal cell cultures from newborn mice
RNAi

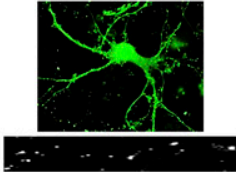

DIV $10+72 h$
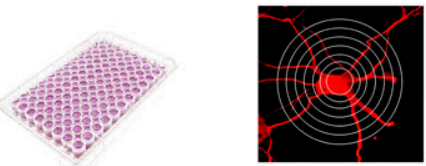

DIV $10+96 h$ DIV $10+120 h$

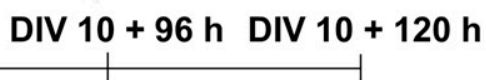

Efficiency of PGRN gene silencing, NMDA/Tau, Spine density

\section{Cell viability Evaluation of neuronal by LDH assay morphology,} PGRN/GIuN2B
B

MOUSE PGRN SIRNA SEQUENCES

1) GAACCAAGUGUUUGCGAAA

2) GUGGAAGGAUGUCGAUUU

3) GUUCACACACGAUGCGUUU

4) GGCCUAGAAUAACGAGCCA
C

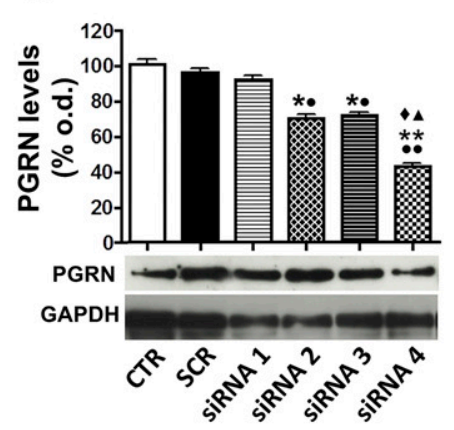

D

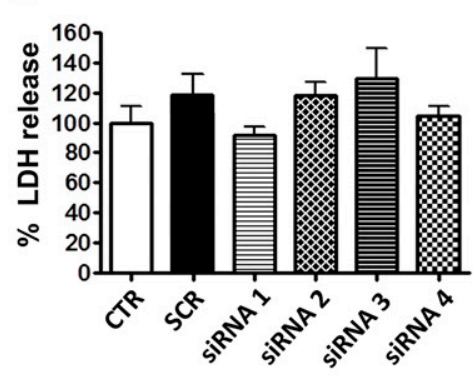

$\mathbf{F}$

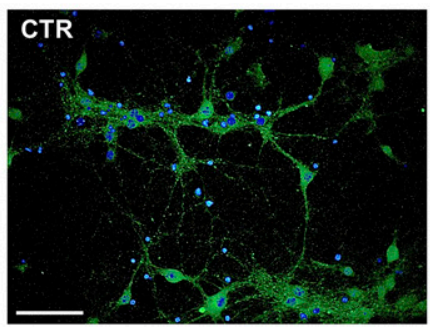

\section{PGRN/Dapi}

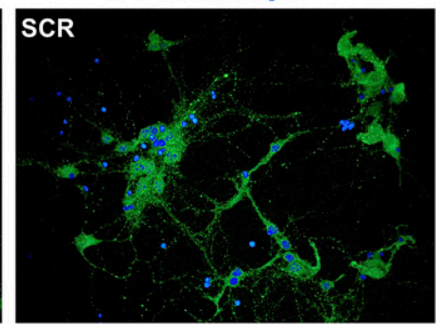

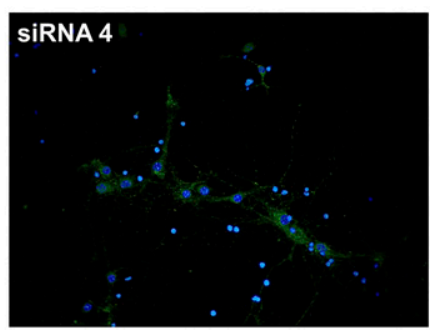

Fig. 3. Evaluation of PGRN gene silencing efficiency. (A) Schematic diagram showing the time-course of the study addressing the effect of PGRN gene silencing in primary cortical neurons. (B) siRNA sequences tested to induce PGRN gene silencing in mouse primary cortical neurons. (C) Histogram showing the efficiency of PGRN gene silencing evaluated as percentage decrease in protein levels in relation to control cells as measured by Western blot. Please note that siRNA sequence number 4 was able to induce the highest degree of PGRN gene silencing compared with both control (CTR) and SCR-treated neurons; ** $P<0.01-60 \%$ vs. CTR, $\bullet P<0.01 \%-55 \%$ vs. SCR. This difference was also statistically significant against siRNA $1(\bullet P<0.01)$ and siRNA 2 and $3(\boldsymbol{\Delta} P<0.05)$. Indeed, siRNA1 did not significantly reduce PGRN levels, and siRNA 2 and siRNA 3 induced only a modest although significant reduction in PGRN levels compared with either control or SCR-treated cells, respectively $(* P<0.05$ vs. CTR; $\bullet P<0.01$ vs. SCR, one-way ANOVA + Newman-Keuls postcomparison test with $N=3$ triplicates for each experimental condition analyzed. (D) Histogram showing the percentage LDH release in relation to control samples as a measure of cell viability and showing that siRNA sequence 4 did not significantly increase LDH release from primary neuronal cells compared with either control or SCRtreated cells (one-way ANOVA + Newman-Keuls postcomparison test with $N=3$ triplicates for each experimental condition analyzed). (E) Representative photomicrographs showing fluorescence PGRN immunoreactivity in primary mouse cortical neurons in basal condition (CTR) after exposure to nonsilencing SCR RNA or siRNA4. Please note the decrease in PGRN immunopositivity in the cells exposed to siRNA4, which is indicative of the specificity of the PGRN signal and the efficiency of silencing of this specific siRNA. Scale bar, $100 \mu \mathrm{m}$.

viability assayed by LDH release assay at 96 hours (Fig. 3D). The reduction in PGRN by siRNA 4 was confirmed by immunocytochemical analysis (Fig. 3E).

\section{PGRN Gene Silencing Reduces GluN2B-Containing NMDAR Density and Expression}

To evaluate whether PGRN gene silencing could influence NMDA receptors we probed whether this could change the membrane levels and density of GluN2B-containing NMDA receptors. The choice to analyze GluN2B-containing NMDA receptors was mostly related to the fact that their expression and clustering in primary cortical neurons appears to be established from DIV 3, whereas GluN2A developmental expression and clustering are delayed and became detectable between DIV 12 and DIV 18 (Li et al., 1998; Mizuta et al., 1998; Desai et al., 2002). In line with these findings, we found that GluN2A was not detectable in primary cortical neurons at DIV 15 (Supplemental Fig. 1A). The levels of GluN1 and GluN2B in the membrane protein extracts were analyzed by Western blot (Fig. 4A). We found that PGRN gene silencing induced a statistically significant reduction in both GluN1 (** $-22.8 \%$; $P<0.01)$ and GluN2B levels (** $-39 \% ; P<0.01)$, as indicated by the reduced density of the immunopositive bands compared with control neurons. Exposure to SCR RNA sequences did not alter GluN1 and GluN2B levels (Fig. 4A). Likewise, GluN1 and GluN2B levels were found to be reduced in total protein extracts produced from siRNA-exposed primary cortical neurons compared with either control or SCR RNA-treated cells (Supplemental Fig. 1B). We also probed whether silenced 


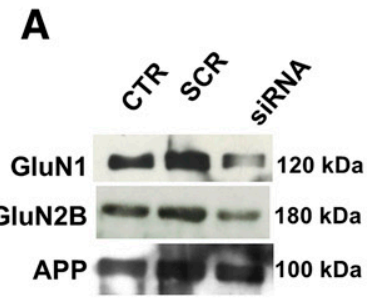

C

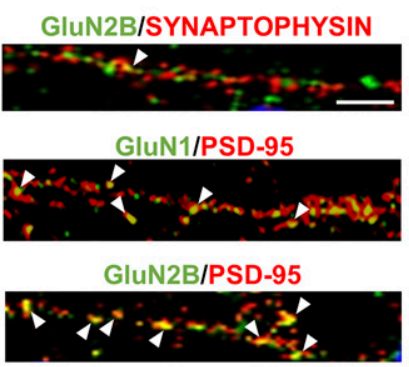

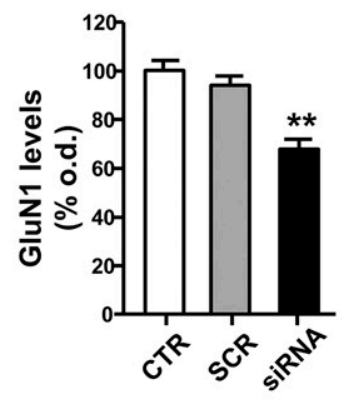

D

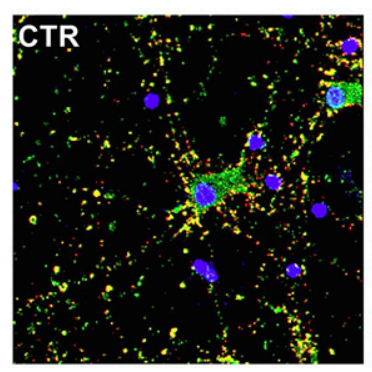

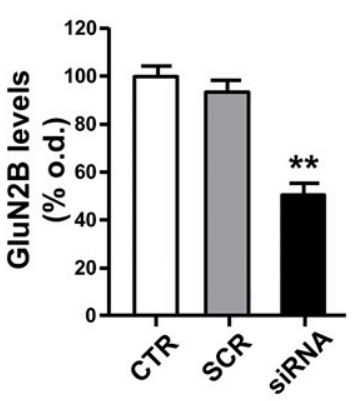

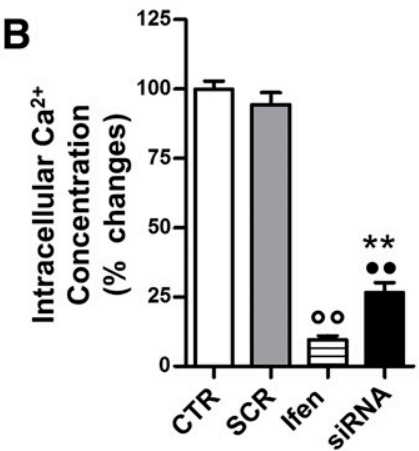

PGRN/GIuN2B/Dapi
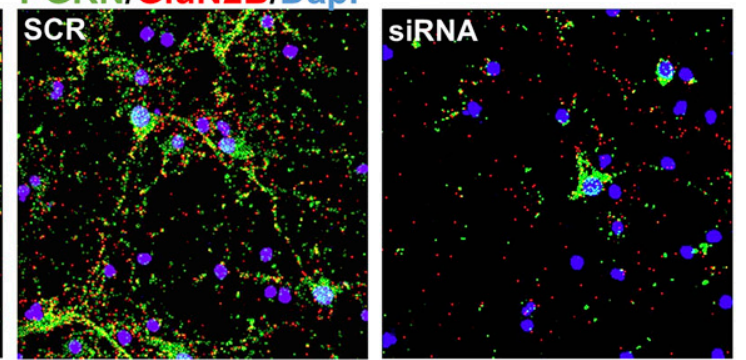
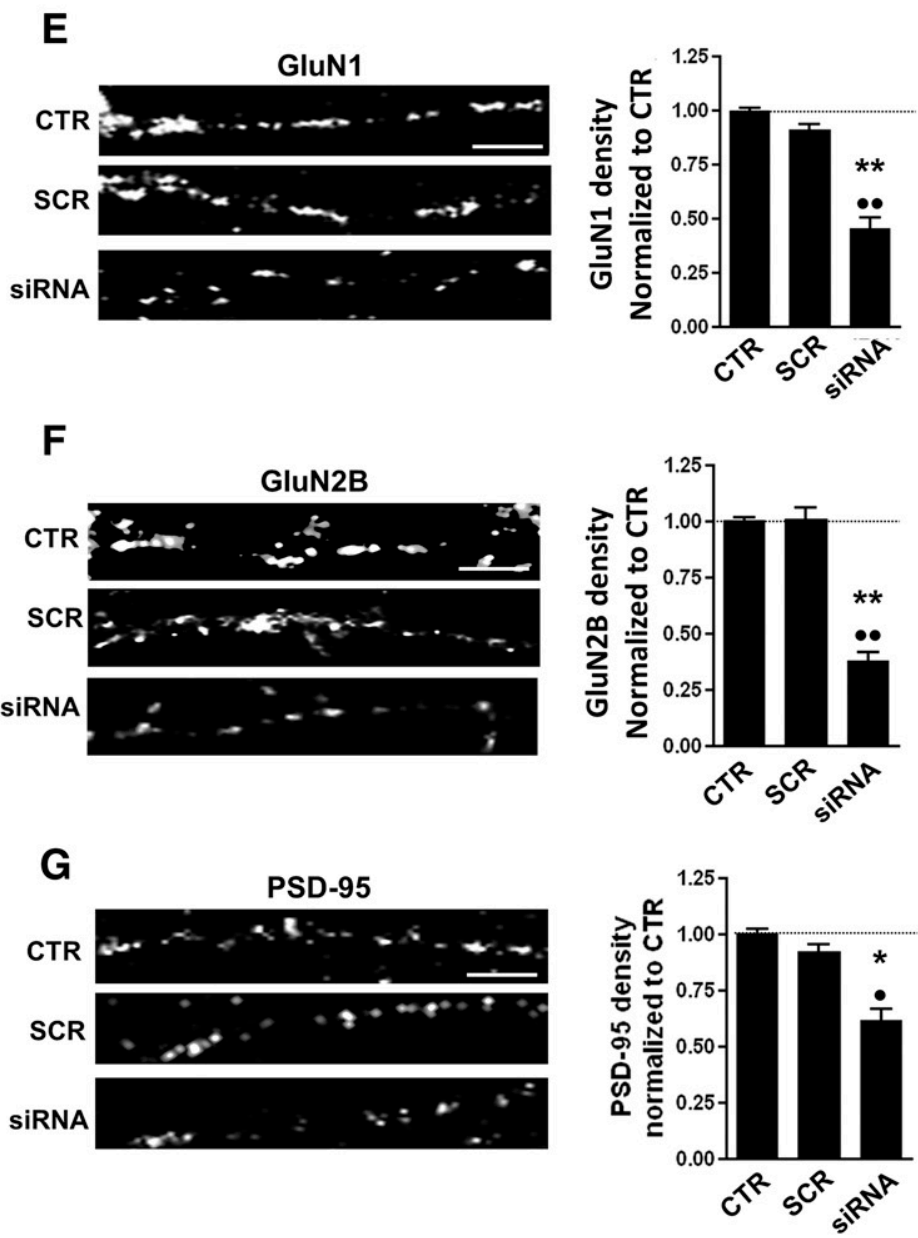

Fig. 4. GluN2B-containing NMDA levels and distribution in control, SCR-, and siRNA-exposed primary mouse cortical neurons at 72 hours from gene silencing. (A) Representative Western blot images showing GluN1, GluN2B, and amyloid precursor protein (APP)-immunopositive Western blot bands from membrane protein extracts of control (CTR), SCR-, or siRNA-exposed neurons are shown on the left. The histograms show the quantification of Western blot immunopositive bands (mean + S.D.) for GluN1 and GluN2B proteins when normalized against APP as a reference membrane protein. ** $P<0.01$ vs. ctr, one-way ANOVA + Newman-Keuls postcomparison test $(N=5$ triplicates for each experimental condition analyzed). (B) Histogram showing the percentage changes (mean $\%$ vs. CTR + S.D.) in intracellular $\mathrm{Ca}^{2+}$ concentration observed in control, SCR-, or siRNA-exposed cortical 
neurons may display decreased activation of GluN2B-containing NMDA receptors after NMDA + glycine exposure. By using the GluN2B selective antagonist ifenprodil we found that NMDA + glycine-induced $\mathrm{Ca}^{2+}$ release from primary cortical neurons was GluN2B-dependent (Fig. 4B). Moreover, we observed that cells exposed to PGRN gene silencing showed a decreased $\mathrm{Ca}^{2+}$ overflow upon NMDA stimulation (Fig. 4B). We also evaluated whether PGRN gene silencing could decrease the levels of $\alpha$-amino-3-hydroxy-5-methyl-4-isoxazolepropionic acid (AMPA) receptors in primary cortical neurons. We found that the cells that were exposed to siRNA did not exhibit a decrease in GluA1 or GluA2 levels (Supplemental Fig. 1C).

We investigated next the colocalization between NMDA receptors with either the presynaptic protein marker synaptophysin or the postsynaptic protein PSD-95 in primary control cortical neurons at DIV 10 (Fig. 4C). The results showed that GluN2B and GluN1 mostly colocalized with the postsynaptic marker PSD-95, whereas NR2B only showed a modest colocalization with synaptophysin, thus indicating that GluN2Bcontaining NMDA receptors were mostly localized at extrasynaptic sites (Fig. 4C). We then probed at 72 hours from gene silencing the density of GluN1, GluN2B, and PSD-95 ICC in neurons that were double-labeled with NMDA and PGRN to ensure that we could measure the changes in relation of PGRN levels (Fig. 4D). The densitometric analysis showed that cells that were exposed to PGRN gene silencing displayed a statistically significant reduction in density of GluN1 (Fig. 4E), GluN2B (Fig. 4F), and PSD-95 (Fig. 4G) compared with control or SCRtreated cells. Finally, since it has been previously described that PGRN depletion can cause a decrease in spine density (Petkau et al., 2012), we also assayed whether the decrease in NR1, NR2B, and PSD-95 might coincide with a reduction in dendritic spines. We found that at 72 hours from siRNA exposure primary neuronal cells showed a statistically significant reduction in spine density compared with either control $(P<0.001)$ or SCR RNA-treated cells $(P<0.01)$ (Supplemental Fig. 1D). These results support the conclusion that the decrease in GluN2Bcontaining NMDA receptors observed after PGRN depletion was associated with a reduction in spine density.

\section{PGRN Gene Silencing Reduces Neuronal Arborization}

Neuronal arborization was analyzed by Sholl analysis (Chen and Firestein, 2007; Kutzing et al., 2010) by evaluating the differences in the number of dendritic intersections between MAP-2-positive control, SCR-exposed and siRNA-exposed neurons at 120 hours from gene silencing. To assess whether GluN2B-containing NMDA receptor stimulation could be involved in the onset of the PGRN gene silencing-dependent decrease in neuronal arborization, we also analyzed siRNAexposed cells that were subjected to acute stimulation with either NMDA + glycine or NMDA + glycine following ifenprodil pretreatment. We found that cells exposed to PGRN gene silencing showed a statistically significant decrease in dendritic intersections (Fig. 5A) at 60, 90, 120, and $150 \mu \mathrm{m}$ from the soma (Fig. 5B). To corroborate the specificity of the effect of PGRN gene silencing on neuronal arborization, we compared the effect of siRNA1, siRNA2, siRNA3, and siRNA4 on this parameter. In line with the data deriving from the evaluation of the gene silencing efficiency of these sequences, we found that siRNA2 and siRNA3 induced a modest increase in neuronal arborization, whereas siRNA4 significantly reduced the number of intersections at 30,60,90,120, and $150 \mu \mathrm{m}$ from the soma compared with siRNA1 (Supplemental Fig. 2, A and B). These observations were corroborated by data showing that the efficiency rate of PGRN gene silencing achieved by using the different siRNA sequences was inversely correlated with the total number of intersections counted for siRNA1, siRNA2, siRNA3, or siRNA4 (Supplemental Fig. 2C).

We then wanted to probe the effect of NMDA stimulation on neuronal arborization in siRNA4-exposed cells. Of note, an acute stimulation of cortical neurons with NMDA + glycine at 24 hours from gene silencing could prevent the effect of PGRN gene silencing on neuronal arborization. Indeed, the NMDA + glycine treated PGRN-silenced neurons showed a weaker, although significant difference in the number of dendritic intersections only at 60 and $90 \mu \mathrm{m}$ from the soma compared with siRNA-exposed cells. Of note, a pretreatment with the GluN2B selective antagonist ifenprodil before the acute stimulation with NMDA + glycine in siRNA-exposed cells was able to significantly prevent the effect of NMDA stimulation on neuronal arborization in the cells exposed to PGRN gene silencing. Finally, we evaluated the persistence of GluN2B decrease in MAP-2 positive cells at 120 hours from gene silencing to ensure they effectively displayed GluN2B reduction. As shown in Fig. 5C we observed a decrease in GluN2B in the siRNA-exposed MAP-2-positive cells but not in control or SCR-treated neurons.

PGRN Gene Silencing Affects NMDA ReceptorDependent Tau Phosphorylation. To evaluate whether PGRN gene silencing could modulate NMDA-dependent tau phosphorylation, we assayed by Western blot tau phosphorylation of Ser 262, 396, and 404 normalized against total tau levels probed by using the tau 46 antibody (Fig. 6A).

We found that PGRN gene silencing significantly reduced the levels of tau phosphorylation in cortical neurons exposed to

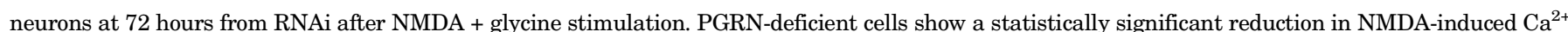

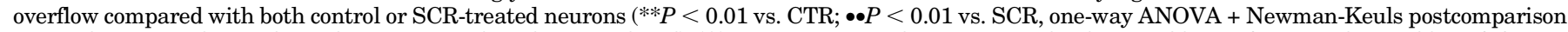

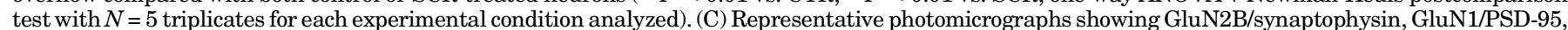

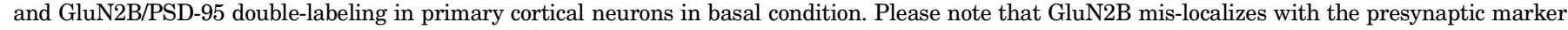

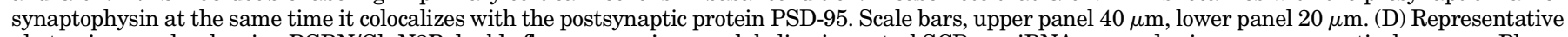

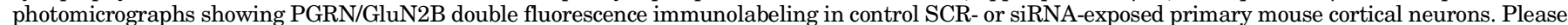

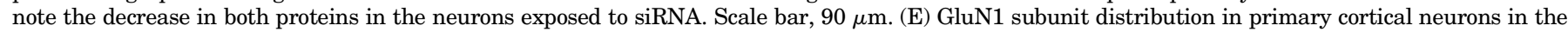

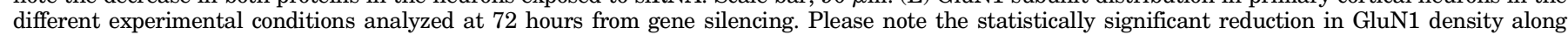

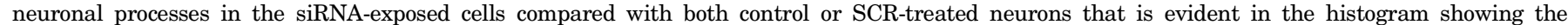

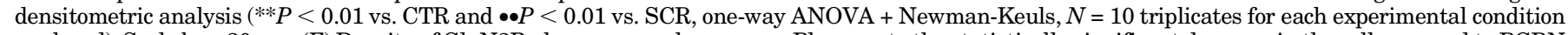

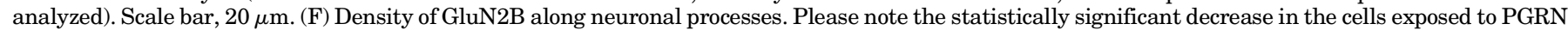

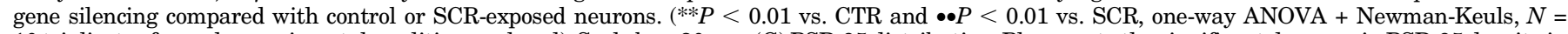

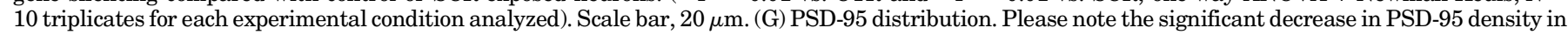

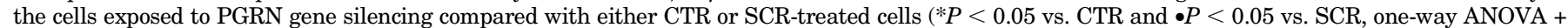
Newman-Keuls, $N=10$ triplicates for each experimental condition analyzed). Scale bar, $20 \mu \mathrm{m}$. 
A

\section{PGRN/MAP2/Dapi/Merge}
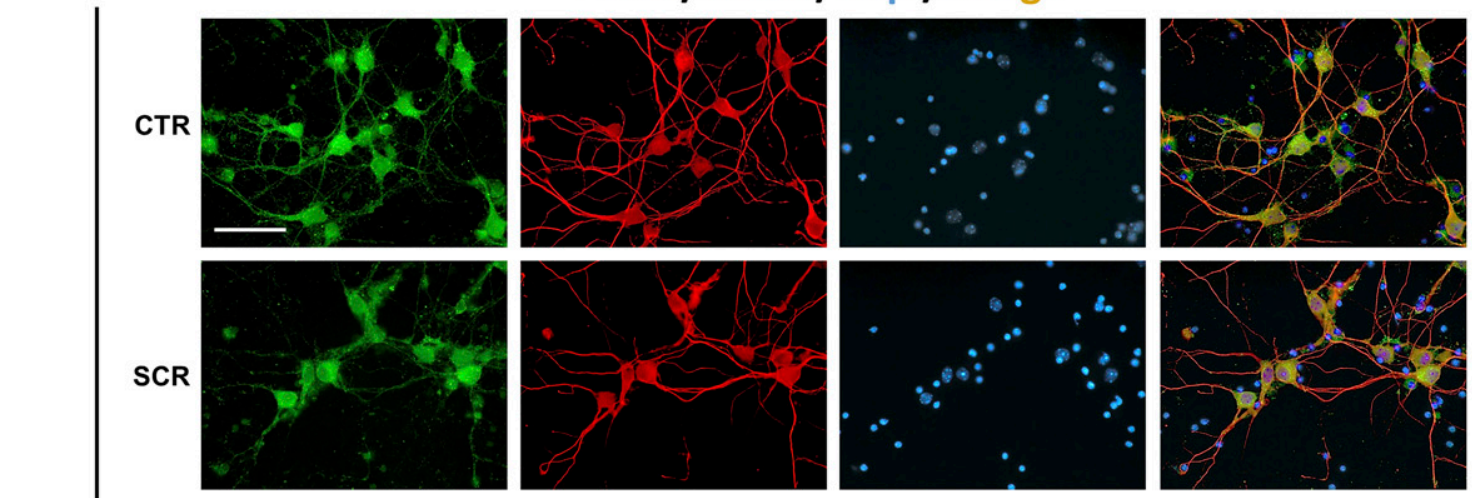

96h
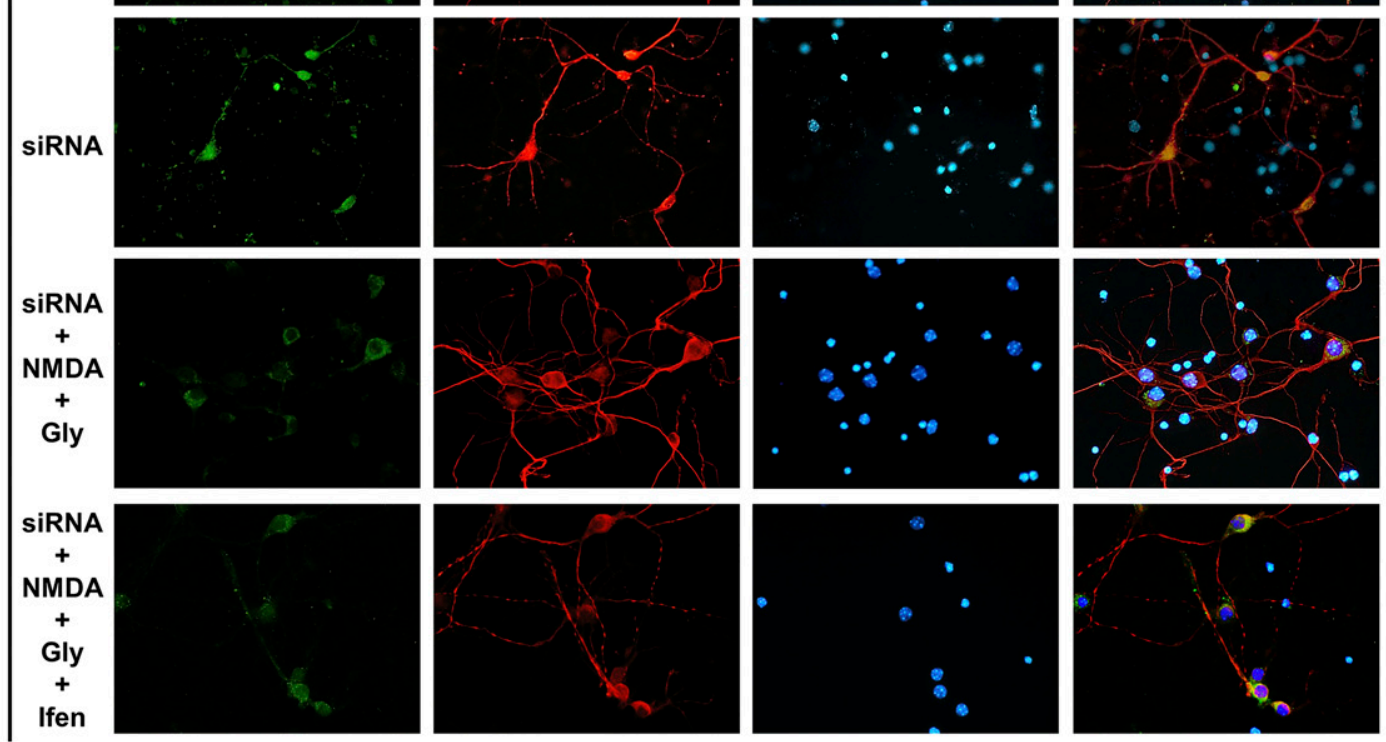

B

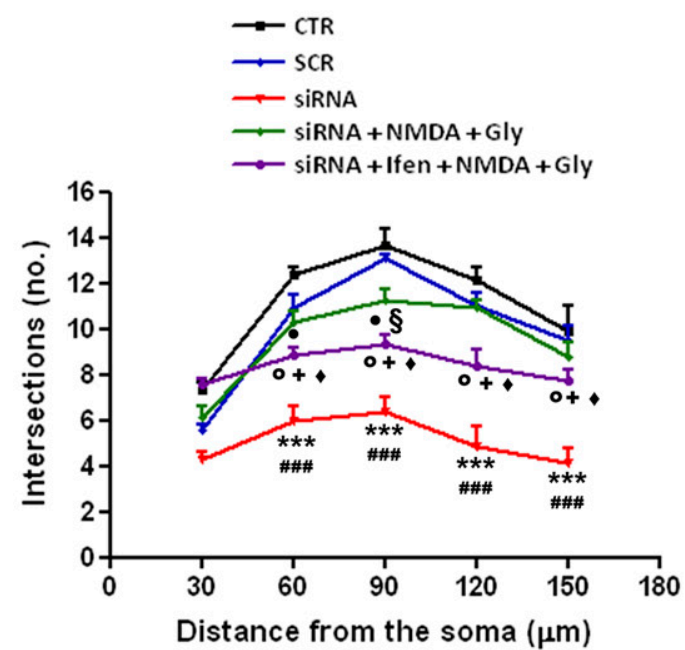

C

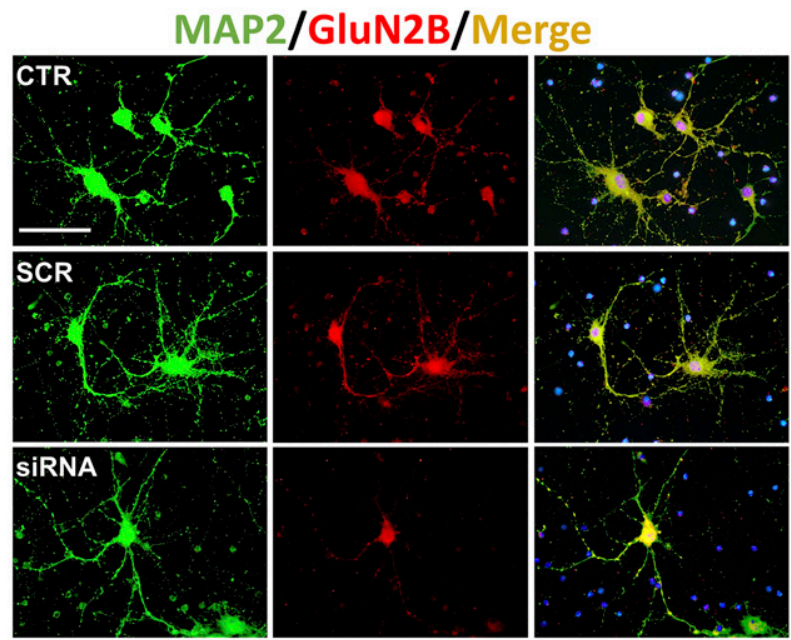

Fig. 5. Analysis of MAP-2-positive cell arborization in primary cortical neurons. (A) Immunofluorescence images showing PGRN/MAP-2 doublelabeling in CTR, SCR-, and siRNA-exposed cells. A fraction of siRNA exposed cells was subjected to NMDA + glycine or ifenprodil (ifen) + NMDA + glycine treatment. Please note that siRNA-exposed neurons show a decrease in neuronal arborization compared with CTR or SCR-treated neurons. Silenced neurons that were treated with NMDA + glycine appeared morphologically similar to controls. However, cells subjected to ifenprodil pretreatment prior NMDA + glycine stimulation were similar to siRNA-exposed neurons. Scale bar, $90 \mu \mathrm{m}$. (B) The graph shows the results of the Scholl analysis. Please note that although siRNA-exposed neurons showed a statistically significant decrease in the number of intersections compared with both CTR and SCR-exposed neurons, in the silenced cells that were subjected to the acute NMDA + glycine (Gly) treatment the arborization was not decreased. The protective effect of NMDA + Gly stimulation was prevented by treatment with the GluN2B 
A

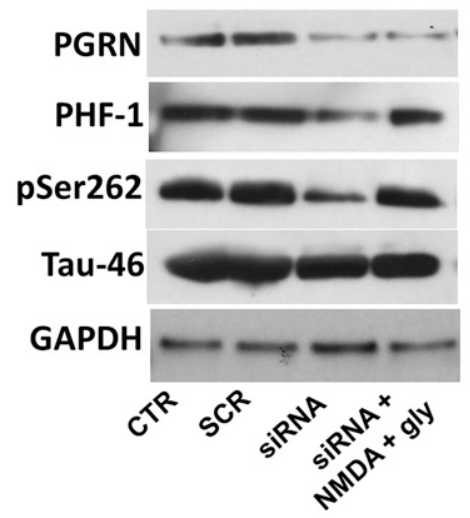

B

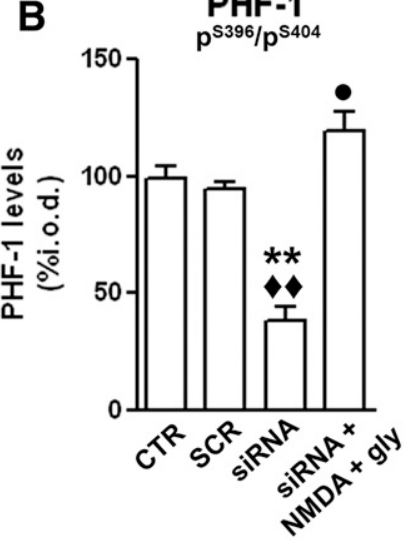

\section{C}

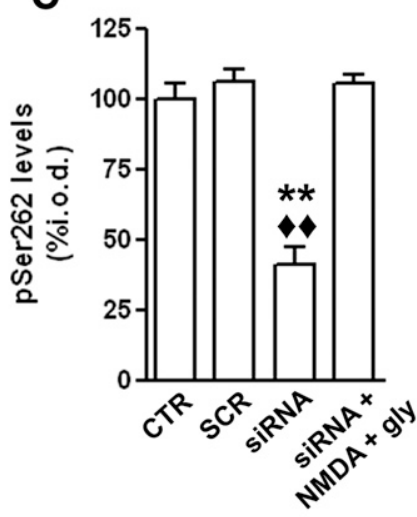

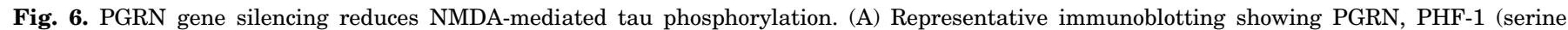

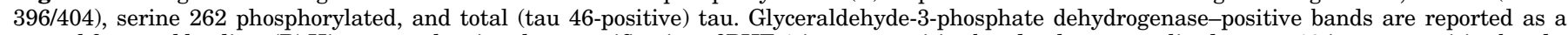

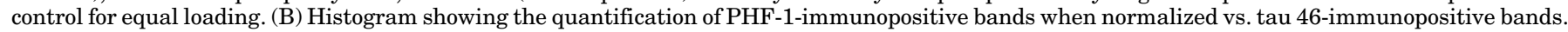

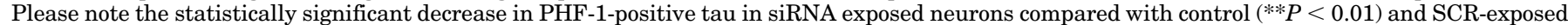

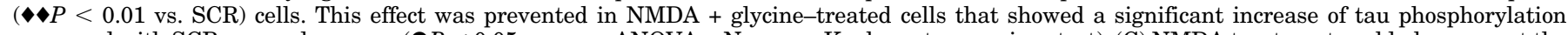

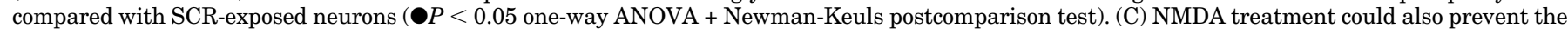

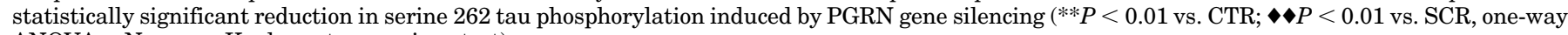
ANOVA + Newman-Keuls postcomparison test).

siRNA compared with control or SCR RNA-treated cells. However, the acute treatment with NMDA + glycine could prevent the reduction in tau phosphorylation in siRNA-exposed neurons, indicating that the abatement of tau phosphorylation was related to the decrease in NMDA receptor levels and activity observed in the cells with PGRN gene silencing.

\section{Discussion}

Collectively, our results indicate that a partial drop of PGRN affects GluN2B-containing NMDA receptor density, tau phosphorylation as well as dendritic arborization in primary mouse cortical neurons. In particular, we found that haploinsufficiencylike PGRN depletion, achieved by RNAi, could reduce GluN1 and GluN2B membrane levels and density at 72 hours from gene silencing. These alterations were associated with a reduction in spine density and NMDA receptor-mediated $\mathrm{Ca}^{2+}$-influx in primary cortical neurons, followed by a decrease in neuronal arborization 96 hours after RNAi. Notably, we found that the decrease in neuronal arborization induced by PGRN gene silencing was prevented by NMDA receptor stimulation, whose effect was in turn reversed by the GluN2B selective antagonist ifenprodil, thereby supporting the existence of a causative link between these phenomena. Indeed, this evidence suggests that the decrease in GluN2B-containing NMDA receptors could mediate the negative effect of PGRN abatement on neuronal trophism. To date, in line with our data, it has been found that, although GluN2B is not essential for dendrite growth and branching, its knockdown is characterized by a decrease in neuronal spine density and the number of apical dendrites (Espinosa et al., 2009), thus suggesting that GluN2B action is relevant for dendrite patterning. In primary cortical neurons in culture at DIV 10, NMDA activity at excitatory synapses is assured by the coupling of GluN1 and GluN2B that can cluster at both synaptic and extrasynaptic sites, with only a very small fraction of synaptic NMDA receptors containing the GluN2A subunit ( $\mathrm{Li}$ et al., 1998). These findings indicate that NMDAdependent regulation of primary cortical neurons is strictly dependent on GluN2B-containing NMDA receptors. In line with this hypothesis and with our findings, inhibition of primary cortical neurons has been found to be associated with dendrite degeneration and reduced ERK1/2 kinase activation in primary neurons (Chernova et al., 2007).

Our results also showed that PGRN gene silencing could decrease GluN2B-containing NMDA receptor-mediated tau phosphorylation at Ser 262 and PHF-1 sites. This observation suggests that PGRN haploinsufficiency, by reducing GluN2Bcontaining NMDA receptor signaling, can affect the structural plasticity of cortical neurons by modulating the ability of tau to interact with microtubules. Indeed, as a result of reduced tau phosphorylation, microtubular networks could be impaired by stiffness, and parallel synapse formation could be hampered, thus generating the loss in neuronal connectivity typical for FTLD. Although further studies are needed to probe this hypothesis, it is well recognized that interaction of tau with microtubules is essential for the proper maintenance of neuronal structural plasticity and for the transport of synaptic cargoes along microtubules. The loss of efficient interaction of tau with microtubules derived from its hyperphosphorylation is implicated in the onset of several neurodegenerative diseases affecting cortical regions, including familial FTLD (Spillantini and Goedert, 2013). Proper tau activity is thus crucial for cortical neuron function and homeostasis, and subtle changes in the posttranslational modifications that drive tau function could severely

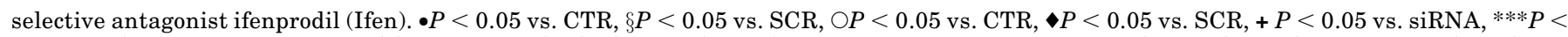

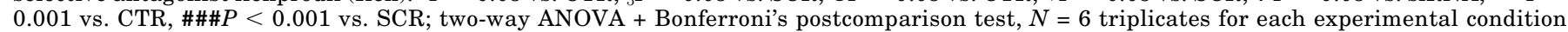

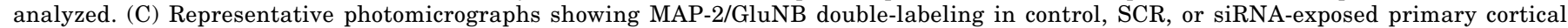
neurons at 96 hours from RNAi. Please note the lower GluN2B-immunopositive signal in the siRNA exposed cells. Scale bar, $90 \mu \mathrm{m}$. 
impinge on cortical neuron resilience. In this scenario, tau hyperphosphorylation, which generates neurofibrillary tangles in Microtubule-Associated Protein Tau-associated FTLD, and tau hypophosphorylation, which results from PGRN reduction in FTLD with PGRN mutations, could be two opposite mechanisms that drive neuronal cells toward degeneration by compromising tau-microtubular interaction. Our results support the conclusion that the reduced activity of NMDA receptors deriving from low PGRN levels could pivotally control the capacity of tau to interact with microtubules in FTLD with PGRN mutations. Notably, several previous research reports have described the occurrence of NMDA receptor-mediated tau phosphorylation in neuronal cells (Zhou et al., 2009; Sava et al., 2012), suggesting that this process could be part of a physiologic intracellular signaling cascade regulating synaptic NMDA receptor-dependent transmission during structural plasticity changes. In particular, NMDA receptors can increase the phosphorylation of tau on specific sites that mediate its interaction with synaptic proteins. Moreover, the phosphorylation of tau controls the interaction of tau with the postsynaptic PSD-95-Fyn-NMDA receptor complex, which regulates GluN2B-containing NMDA-dependent synaptic plasticity, suggesting that physiologically occurring phosphorylation of tau could serve as a regulatory mechanism to prevent NMDA receptor overexcitation (Mondragon-Rodriguez et al., 2012). These findings, coupled to our results, hint that a decrease in PGRN increases neuronal vulnerability by leading to a reduction in GluN2Bcontaining NMDA receptors, which in turn affects the rate of tau phosphorylation and might perturb the ability of neuronal cells to easily display structural plasticity changes. Structural changes occur in the brain throughout life, including the generation of new neurons and other brain cells and connections between and among neurons, and structural plasticity provides the mechanism for the brain to repair itself (Gage, 2004). In addition, subtle changes in functional plasticity in brain cortical areas can contribute to behavioral impairments in the absence of significant pathology (Burke and Barnes, 2006). This implies that in PGRN mutation carriers, cortical neurons holding reduced PGRN levels may present a lower ability to display structural plasticity changes. This phenomenon may also significantly decrease the resilience of these cells to aging and stressors.

Consistent with our conclusions are recent reports that PGRN-deficient mice display reduced synaptic connectivity and plasticity impairment occurring before neuropathological abnormalities (Petkau et al., 2012). Moreover, PGRN deficiency reduces synaptic pruning in the thalamus by dysregulating microglial cells (Lui et al., 2016). Our findings show that the PGRN-deficiency-related decrease in neuronal arborization is attributable to a decrease in NR2B-containing NMDA receptors that is paralleled by a decrease in spine density. This evidence is in tune with previous findings showing that, although PGRN reduction can enhance transmission at individual synapses, it decreases gross neuronal connectivity (Tapia et al., 2011), and confirms that important neuronal plasticity changes occur in the early stages of disease. Remarkably, both NMDA receptor activity and tau phosphorylation have been found to be highly involved in the control of microtubule dynamic changes during neuronal structural plasticity (Caceres and Kosik, 1990; Knops et al., 1991; Biernat and Mandelkow, 1999; Dawson et al., 2001).

Worthy of note, a recent finding indicates that PGRN reduction is associated with increased tau phosphorylation in P301L transgenic mice (Hosokawa et al., 2015). Although in part these observations are not in agreement with our results, which indicate that a decrease in PGRN reduces tau phosphorylation, it is feasible that other mechanisms may be involved in the opposite phenomenon in the transgenic P301L tau model. This is supported by the fact that PGRN-deficient mice do not show tau hyperphosphorylation (Hosokawa et al., 2015). In addition, we cannot exclude that a partial reduction in PGRN resulting in the case of haploinsufficiency may affect neuronal homeostasis in a manner completely different from the complete absence of the protein, as supported by the different pathologic phenotypes described for PGRN-knockout and PGRN-insufficient mice (Yin et al., 2010; Martens et al., 2012; Petkau et al., 2012; Filiano et al., 2013; Arrant et al., 2015). Data in human cerebrospinal fluids further support our experimental evidence, as we previously described that tau phosphorylation is increased in Alzheimer's disease patients and in FTLD patients compared with controls but not in FTLD patients carrying a GRN mutation that causes progranulin haploinsufficiency (Carecchio et al., 2011).

The results of this study indicate that an haploinsufficiencylike decrease in PGRN can reduce the density and activity of GluN2B-containing NMDA receptors. This phenomenon is associated with a reduction in NMDA receptor-mediated tau phosphorylation as well as a loss of neuronal dendritic arborization, which is reversible by an acute GluN2B-containing NMDA receptor stimulation at 24 hours from gene silencing. These findings support the conclusions that GluN2Bcontaining NMDA receptors could be crucial mediators for the control of PGRN-dependent cortical neuron neurotrophism.

Collectively, these observations suggest that an aberrant regulation of GluN2B-containing NMDA receptors resulting from PGRN loss of function mutations could impinge on cortical neuron resilience by perturbing their ability to display structural plasticity changes. The resulting progressive decline of neuronal trophism could probably initiate neurodegeneration in FTLD with GRN mutations.

These observations have relevant implications for understanding the molecular mechanisms underlying the onset of FTLD.

\section{Acknowledgments}

The authors are grateful to Alessandro Barbon for providing the GluN2A, GluA1, and GluA2 antibodies.

\section{Authorship Contributions}

Participated in research design: Bellucci, Spano, Zaltieri.

Conducted experiments: Bellucci, Longhena, Zaltieri, Grigoletto, Faustini, La Via.

Performed data analysis: Longhena, Zaltieri, Grigoletto.

Wrote or contributed to the writing of the manuscript: Bellucci, Longhena, Ghidoni, Benussi, Spano, Missale.

\section{References}

Arendt T, Stieler J, and Holzer M (2015) Brain hypometabolism triggers PHF-like phosphorylation of tau, a major hallmark of Alzheimer's disease pathology. $J$ Neural Transm (Vienna) 122:531-539.

Arrant AE, Patel AR, and Roberson ED (2015) Effects of exercise on progranulin levels and gliosis in progranulin-insufficient mice. eNeuro 2:1-12 DOI: https://doi. org/10.1523/ENEURO.0061-14.2015.

Baker M, Mackenzie IR, Pickering-Brown SM, Gass J, Rademakers R, Lindholm C, Snowden J, Adamson J, Sadovnick AD, Rollinson S, et al. (2006) Mutations in progranulin cause tau-negative frontotemporal dementia linked to chromosome 17. Nature 442:916-919.

Benussi L, Ciani M, Tonoli E, Morbin M, Palamara L, Albani D, Fusco F, Forloni G,

Glionna M, Baco M, et al. (2016) Loss of exosomes in progranulin-associated frontotemporal dementia. Neurobiol Aging 40:41-49.

Biernat J and Mandelkow EM (1999) The development of cell processes induced by tau protein requires phosphorylation of serine 262 and 356 in the repeat domain and is inhibited by phosphorylation in the proline-rich domains. Mol Biol Cell 10:727-740. 
Borroni B, Alberici A, Cercignani M, Premi E, Serra L, Cerini C, Cosseddu M, Pettenati C, Turla M, Archetti S, et al. (2012) Granulin mutation drives brain damage and reorganization from preclinical to symptomatic FTLD. Neurobiol Aging 33:2506-2520.

Bozzali M, Battistoni V, Premi E, Alberici A, Giulietti G, Archetti S, Turla M, Gasparotti R, Cercignani M, Padovani A, et al. (2013) Structural brain signature of FTLD driven by Granulin mutation. J Alzheimers Dis 33:483-494.

Burke SN and Barnes CA (2006) Neural plasticity in the ageing brain. Nat Rev Neurosci 7:30-40.

Caceres A and Kosik KS (1990) Inhibition of neurite polarity by tau antisense oligonucleotides in primary cerebellar neurons. Nature 343:461-463.

Carecchio M, Fenoglio C, Cortini F, Comi C, Benussi L, Ghidoni R, Borroni B, De Riz M, Serpente M, Cantoni C, et al. (2011) Cerebrospinal fluid biomarkers in Progranulin mutations carriers. J Alzheimers Dis 27:781-790.

Carpenter-Hyland EP and Chandler LJ (2007) Adaptive plasticity of NMDA receptors and dendritic spines: implications for enhanced vulnerability of the adolescent brain to alcohol addiction. Pharmacol Biochem Behav 86:200-208.

Chen $\mathrm{H}$ and Firestein BL (2007) RhoA regulates dendrite branching in hippocampal neurons by decreasing cypin protein levels. $J$ Neurosci 27:8378-8386.

Chernova T, Steinert JR, Guerin CJ, Nicotera P, Forsythe ID, and Smith AG (2007) Neurite degeneration induced by heme deficiency mediated via inhibition of NMDA receptordependent extracellular signal-regulated kinase 1/2 activation. $J$ Neurosci 27:8475-8485.

Chitramuthu BP, Baranowski DC, Kay DG, Bateman A, and Bennett HP (2010) Progranulin modulates zebrafish motoneuron development in vivo and rescues truncation defects associated with knockdown of Survival motor neuron 1. Mol Neurodegener 5:41.

Cruts M, Gijselinck I, van der Zee J, Engelborghs S, Wils H, Pirici D, Rademakers R, Vandenberghe R, Dermaut B, Martin JJ, et al. (2006) Null mutations in progranulin cause ubiquitin-positive frontotemporal dementia linked to chromosome 17q21. Nature 442:920-924.

Dawson HN, Ferreira A, Eyster MV, Ghoshal N, Binder LI, and Vitek MP (2001) Inhibition of neuronal maturation in primary hippocampal neurons from tau deficient mice. J Cell Sci 114:1179-1187.

Desai A, Turetsky D, Vasudevan K, and Buonanno A (2002) Analysis of transcriptional regulatory sequences of the N-methyl-D-aspartate receptor $2 \mathrm{~A}$ subunit gene in cultured cortical neurons and transgenic mice. $J$ Biol Chem 277:46374-46384.

El Gaamouch F, Buisson A, Moustié O, Lemieux M, Labrecque S, Bontempi B, De Koninck P, and Nicole O (2012) Interaction between $\alpha$ CaMKII and GluN2B controls ERK-dependent plasticity. J Neurosci 32:10767-10779.

Espinosa JS, Wheeler DG, Tsien RW, and Luo L (2009) Uncoupling dendrite growth and patterning: single-cell knockout analysis of NMDA receptor 2B. Neuron 62:205-217.

Filiano AJ, Martens LH, Young AH, Warmus BA, Zhou P, Diaz-Ramirez G, Jiao J, Zhang Z, Huang EJ, Gao FB, et al. (2013) Dissociation of frontotemporal dementiarelated deficits and neuroinflammation in progranulin haploinsufficient mice. $J$ Neurosci 33:5352-5361.

Finch N, Baker M, Crook R, Swanson K, Kuntz K, Surtees R, Bisceglio G, RoveletLecrux A, Boeve B, Petersen RC, et al. (2009) Plasma progranulin levels predict progranulin mutation status in frontotemporal dementia patients and asymptomatic family members. Brain 132:583-591.

Gage FH (2004) Structural plasticity of the adult brain. Dialogues Clin Neurosci 6 135-141.

Ghidoni R, Benussi L, Glionna M, Franzoni M, and Binetti G (2008) Low plasma progranulin levels predict progranulin mutations in frontotemporal lobar degeneration. Neurology 71:1235-1239.

Ghidoni R, Paterlini A, Albertini V, Binetti G, and Benussi L (2012) Losing protein in the brain: the case of progranulin. Brain Res 1476:172-182.

Gijselinck I, van der Zee J, Engelborghs S, Goossens D, Peeters K, Mattheijssens M, Corsmit E, Del-Favero J, De Deyn PP, Van Broeckhoven C, et al. (2008) Progranulin locus deletion in frontotemporal dementia. Hum Mutat 29:53-58.

Hosokawa M, Arai T, Masuda-Suzukake M, Kondo H, Matsuwaki T, Nishihara M, Hasegawa M, and Akiyama H (2015) Progranulin reduction is associated with increased tau phosphorylation in P301L tau transgenic mice. J Neuropathol Exp Neurol 74:158-165.

Jian J, Konopka J, and Liu C (2013) Insights into the role of progranulin in immunity, infection, and inflammation. J Leukoc Biol 93:199-208.

Knops J, Kosik KS, Lee G, Pardee JD, Cohen-Gould L, and McConlogue L (1991) Overexpression of tau in a nonneuronal cell induces long cellular processes. $J$ Cell Biol 114:725-733.

Kutzing MK, Langhammer CG, Luo V, Lakdawala H, and Firestein BL (2010) Automated Sholl analysis of digitized neuronal morphology at multiple scales. $J$ Vis Exp 45: e2354.

Laird AS, Van Hoecke A, De Muynck L, Timmers M, Van den Bosch L, Van Damme $\mathrm{P}$, and Robberecht W (2010) Progranulin is neurotrophic in vivo and protects against a mutant TDP-43 induced axonopathy. PLoS One 5:e13368.

Laulagnier K, Javalet C, Hemming FJ, and Sadoul R (2017) Purification and analysis of exosomes released by mature cortical neurons following synaptic activation. Methods Mol Biol 1545:129-138.

Laurier-Laurin ME, De Montigny A, Attiori Essis S, Cyr M, and Massicotte G (2014) Blockade of lysosomal acid ceramidase induces GluN2B-dependent tau phosphorylation in rat hippocampal slices. Neural Plast 2014:196812.

Li JH, Wang YH, Wolfe BB, Krueger KE, Corsi L, Stocca G, and Vicini S (1998) Developmental changes in localization of NMDA receptor subunits in primary cultures of cortical neurons. Eur J Neurosci 10:1704-1715.

Lui H, Zhang J, Makinson SR, Cahill MK, Kelley KW, Huang HY, Shang Y, Oldham MC, Martens LH, Gao F, et al. (2016) Progranulin deficiency promotes circuit-specific synaptic pruning by microglia via complement activation. Cell 165:921-935

Martens LH, Zhang J, Barmada SJ, Zhou P, Kamiya S, Sun B, Min SW, Gan L, Finkbeiner S, Huang EJ, et al. (2012) Progranulin deficiency promotes neuroinflammation and neuron loss following toxin-induced injury. J Clin Invest 122:3955-3959.

McKhann GM, Albert MS, Grossman M, Miller B, Dickson D, and Trojanowski JQ Work Group on Frontotemporal Dementia and Pick's Disease (2001) Clinical and pathological diagnosis of frontotemporal dementia: report of the Work Group on Frontotemporal Dementia and Pick's Disease. Arch Neurol 58:1803-1809.
Mizuta I, Katayama M, Watanabe M, Mishina M, and Ishii K (1998) Developmental expression of NMDA receptor subunits and the emergence of glutamate neurotoxicity in primary cultures of murine cerebral cortical neurons. Cell $\mathrm{Mol}$ Life Sci 54:721-725.

Mondragón-Rodríguez S, Trillaud-Doppia E, Dudilot A, Bourgeois C, Lauzon M, Leclerc N, and Boehm J (2012) Interaction of endogenous tau protein with synaptic proteins is regulated by N-methyl-D-aspartate receptor-dependent tau phosphorylation. J Biol Chem 287:32040-32053.

Mony L, Kew JN, Gunthorpe MJ, and Paoletti P (2009) Allosteric modulators of NR2B-containing NMDA receptors: molecular mechanisms and therapeutic potential. Br J Pharmacol 157:1301-1317.

Moretti DV, Benussi L, Fostinelli S, Ciani M, Binetti G, and Ghidoni R (2016) Progranulin mutations affects brain oscillatory activity in fronto-temporal dementia. Front Aging Neurosci 8:35.

Navarria L, et al. (2015) Alpha-synuclein modulates NR2B-containing NMDA receptors and decreases their levels after rotenone exposure. Neurochem Int 85-86:14-23.

Petkau TL, Hill A, and Leavitt BR (2016) Core neuropathological abnormalities in progranulin-deficient mice are penetrant on multiple genetic backgrounds. Neuroscience 315:175-195.

Petkau TL and Leavitt BR (2014) Progranulin in neurodegenerative disease. Trends Neurosci 37:388-398.

Petkau TL, Neal SJ, Milnerwood A, Mew A, Hill AM, Orban P, Gregg J, Lu G, Feldman HH, Mackenzie IR, et al. (2012) Synaptic dysfunction in progranulindeficient mice. Neurobiol Dis 45:711-722.

Petkau TL, Neal SJ, Orban PC, MacDonald JL, Hill AM, Lu G, Feldman HH Mackenzie IR, and Leavitt BR (2010) Progranulin expression in the developing and adult murine brain. J Comp Neurol 518:3931-3947.

Pievani M, Paternicò D, Benussi L, Binetti G, Orlandini A, Cobelli M, Magnaldi S, Ghidoni R, and Frisoni GB (2014) Pattern of structural and functional brain abnormalities in asymptomatic granulin mutation carriers. Alzheimers Dement 10 (Suppl 5)S354-S363, 363.e1.

Rohrer JD, Geser F, Zhou J, Gennatas ED, Sidhu M, Trojanowski JQ, Dearmond SJ, Miller BL, and Seeley WW (2010) TDP-43 subtypes are associated with distinct atrophy patterns in frontotemporal dementia. Neurology 75:2204-2211.

Rohrer JD, Nicholas JM, Cash DM, van Swieten J, Dopper E, Jiskoot L, van Minkelen R, Rombouts SA, Cardoso MJ, Clegg S, et al. (2015) Presymptomatic cognitive and neuroanatomical changes in genetic frontotemporal dementia in the Genetic Frontotemporal dementia Initiative (GENFI) study: a cross-sectional analysis. Lancet Neurol 14:253-262.

Rohrer JD, Warren JD, Fox NC, and Rossor MN (2013) Presymptomatic studies in genetic frontotemporal dementia. Rev Neurol (Paris) 169:820-824.

Ryan CL, Baranowski DC, Chitramuthu BP, Malik S, Li Z, Cao M, Minotti S, Durham HD, Kay DG, Shaw CA, et al. (2009) Progranulin is expressed within motor neurons and promotes neuronal cell survival. BMC Neurosci 10:130.

Sava A, Formaggio E, Carignani C, Andreetta F, Bettini E, and Griffante C (2012) NMDA-induced ERK signalling is mediated by NR2B subunit in rat cortical neurons and switches from positive to negative depending on stage of development. Neuropharmacology 62:925-932.

Skoglund L, Matsui T, Freeman SH, Wallin A, Blom ES, Frosch MP, Growdon JH, Hyman BT, Lannfelt L, Ingelsson M, et al. (2011) Novel progranulin mutation detected in 2 patients with FTLD. Alzheimer Dis Assoc Disord 25:173-178.

Sleegers K, Brouwers N, Van Damme P, Engelborghs S, Gijselinck I, van der Zee J, Peeters K, Mattheijssens M, Cruts M, Vandenberghe R, et al. (2009) Serum biomarker for progranulin-associated frontotemporal lobar degeneration. Ann Neurol 65:603-609. Spillantini MG and Goedert M (2013) Tau pathology and neurodegeneration. Lancet Neurol 12:609-622.

Stein IS, Gray JA, and Zito K (2015) Non-ionotropic NMDA receptor signaling drives activity-induced dendritic spine shrinkage. J Neurosci 35:12303-12308.

Tackenberg C, Grinschgl S, Trutzel A, Santuccione AC, Frey MC, Konietzko U, Grimm J, Brandt R, and Nitsch RM (2013) NMDA receptor subunit composition determines beta-amyloid-induced neurodegeneration and synaptic loss. Cell Death Dis 4:e608.

Tapia L, Milnerwood A, Guo A, Mills F, Yoshida E, Vasuta C, Mackenzie IR, Raymond L, Cynader M, Jia W, et al. (2011) Progranulin deficiency decreases gross neural connectivity but enhances transmission at individual synapses. $J$ Neurosci 31:11126-11132.

Van Damme P, Van Hoecke A, Lambrechts D, Vanacker P, Bogaert E, van Swieten J, Carmeliet P, Van Den Bosch L, and Robberecht W (2008) Progranulin functions as a neurotrophic factor to regulate neurite outgrowth and enhance neuronal survival. J Cell Biol 181:37-41.

Whitwell JL, Jack CR, Jr, Baker M, Rademakers R, Adamson J, Boeve BF, Knopman DS, Parisi JF, Petersen RC, Dickson DW, et al. (2007) Voxel-based morphometry in frontotemporal lobar degeneration with ubiquitin-positive inclusions with and without progranulin mutations. Arch Neurol 64:371-376.

Williams JM, Guévremont D, Kennard JT, Mason-Parker SE, Tate WP, and Abraham WC (2003) Long-term regulation of N-methyl-D-aspartate receptor subunits and associated synaptic proteins following hippocampal synaptic plasticity. Neuroscience 118:1003-1013.

Wyllie DJ, Livesey MR, and Hardingham GE (2013) Influence of GluN2 subunit identity on NMDA receptor function. Neuropharmacology 74:4-17.

Yin F, Banerjee R, Thomas B, Zhou P, Qian L, Jia T, Ma X, Ma Y, Iadecola C, Beal $\mathrm{MF}$, et al. (2010) Exaggerated inflammation, impaired host defense, and neuropathology in progranulin-deficient mice. J Exp Med 207:117-128.

Zhou X, Moon C, Zheng F, Luo Y, Soellner D, Nuñez JL, and Wang H (2009) Nmethyl-D-aspartate-stimulated ERK1/2 signaling and the transcriptional up-regulation of plasticity-related genes are developmentally regulated following in vitro neuronal maturation. J Neurosci Res 87:2632-2644.

Address correspondence to: Dr. Arianna Bellucci, Division of Pharmacology, Department of Molecular and Translational Medicine, University of Brescia Viale Europa no. 11, 25123, Brescia, Italy. E-mail: arianna.bellucci@unibs.it 